\title{
Quantification of spontaneous locomotion activity in foals kept in pastures under various management conditions
}

\author{
C. M. H. Chantal Kurvers, DVM; P. René van Weeren, DVM, PhD; Chris W. Rogers, PhD; \\ Machteld C. van Dierendonck, PhD
}

\begin{abstract}
Objective-To describe spontaneous locomotion activity of foals kept under various management conditions and assess the suitability of global positioning system (GPS) technology for recording foal activity.
\end{abstract}

Animals-59 foals.

Procedures-During the foals' first 4 months of life, 921 observation periods (15 minutes each) were collected and analyzed for locomotion activities. The GPS system was evaluated by simultaneously carrying out field observations with a handheld computer.

Results-Foals spent $0.5 \%$ of total observed time cantering, $0.2 \%$ trotting, $10.7 \%$ walking, $32.0 \%$ grazing, $34.8 \%$ standing, and $21.6 \%$ lying down. Total observed daytime workload (velocity $X$ distance) in the first month was approximately twice that in the following months. Locomotion activity decreased with increasing age. Colts had more activity than fillies in certain periods, and foals that were stabled for some portion of the day had compensatory locomotion activity, which was probably insufficient to reach the level of foals kept continually outside. The GPS recordings and handheld-computer observations were strongly correlated for canter, trot, and walk and moderately correlated for standing and lying. Correlation for grazing was low.

Conclusions and Clinical Relevance-Results indicated that domestically managed foals, when kept 24 $\mathrm{h} / \mathrm{d}$ at pasture, will exercise at a level comparable with feral foals. High workload during the first month of life might be important for conditioning the musculoskeletal system. The GPS technique accurately quantified canter, trot, and walk activities; less accurately indexed resting; and was unsuitable for grazing because of the wide array of velocities used while foraging. (Am J Vet Res 2006;67:1212-1217)

$P^{1}$ lay behavior and bouts of high-speed exercise are considered to be important for correct development of motion patterns and coordinative capacities in juvenile animals. ${ }^{1}$ Recent research has identified that exer-

Received November 1, 2005

Accepted December 30, 2005.

From the Departments of Equine Sciences (Kurvers, van Weeren) and Animal, Science, and Society (van Dierendonck), Faculty of Veterinary Medicine, Utrecht University, Yalelaan 12, NL 3584 CM Utrecht, The Netherlands; and Institute of Veterinary, Animal, and Biomedical Sciences, Massey University, Palmerston North, New Zealand (Rogers). Dr. Kurvers' present address is Dijk 17, NL 6127 AG Grevenbicht, The Netherlands.

Supported by the New Zealand Equine Research Foundation.

The authors thank F. Sanders and A. Klarenbeek for technical assistance.

Address correspondence to Dr. Kurvers.

\begin{tabular}{ll}
\hline \multicolumn{1}{c}{ AbBreViations } \\
GPS & Global positioning system \\
VMS & Vehicle memory system \\
\hline
\end{tabular}

cise in early life is also essential for correct development of some musculoskeletal tissues. Exercise at a young age is important for conditioning the collagen network in articular cartilage, and in humans, it has been suggested that too little exercise during the juvenile period may lead to inferior tissue quality and, thus, to increased risk of development of chronic debilitating joint diseases such as osteoarthritis. ${ }^{2}$ In horses, the positive effect of early exercise on the musculoskeletal system was indicated by results of a study ${ }^{3}$ that examined the interaction of early exercise and osteochondrosis. Lack of exercise (box stall rest) appeared to delay development of most tissues of the equine musculoskeletal system. When exercise was increased after 5 months of enforced box stall rest, most tissues had compensatory development, but total collagen and some posttranslational modifications of the collagen network of the extracellular matrix of articular cartilage did not. ${ }^{4,5}$ In a trial conducted by the Global Equine Research Alliance, ${ }^{6}$ exercise in addition to free-pasture exercise was given to a group of young New Zealand Thoroughbreds. Preliminary data from this project suggest that exercise at foal age may influence the biochemical makeup of articular cartilage and, thus, the quality of the tissue. ${ }^{7,8}$

With ample evidence for the crucial role of exercise at an early age, there are few data to provide a basis for recommendations with respect to the amount and character of the exercise required. It can be presumed that under wild, or at least feral, conditions, foals exercise themselves sufficiently to attain optimal musculoskeletal tissue development. A few studies ${ }^{9,10}$ have examined locomotion activity in semiferal juvenile horses and provided data that could be considered as reference points. However, most domesticated juvenile horses are kept under different conditions. The first logical step in the development of science-based exercise protocols for juvenile horses that aim at optimal conditioning of the musculoskeletal tissues would be the evaluation of exercise levels under present-day management conditions and comparison with patterns described in semiferal horses. A modern and promising technique to quantify animal locomotion, which is much less labor intensive than classic observational studies, is the use of the GPS, a satellite-based naviga- 
tion system consisting of 27 earth-orbiting satellites. In animal locomotion studies, ${ }^{11-17}$ the technique has been used principally to monitor trekking routes and pasture use. The purpose of the study reported here was to quantify the exercise attributable to voluntary movement in Warmblood foals kept under common management conditions for domesticated horses. The hypothesis tested was that domestically managed foals, if kept at pasture for $24 \mathrm{~h} / \mathrm{d}$, would have similar exercise patterns as foals in semiferal conditions but that certain management aspects (hours at pasture and group size) would influence this variable. An additional goal of the investigation, which was carried out in the form of a preliminary study, was to evaluate the suitability of the GPS technique for correct determination of various activities of foals at pasture.

\section{Materials and Methods}

GPS study-Eighty hours of GPS recordings were obtained on Thoroughbred foals in Palmerston North $\left(40^{\circ} 23^{\prime} \mathrm{S}, 175^{\circ} 37^{\prime} \mathrm{E}\right)$, New Zealand. The GPS receivers were placed on the foals and recorded their velocity (and position) every second. The raw data files were transferred to a laptop computer. During 2 hours, simultaneous with the GPS data collection, 2 foals were visually observed and activities were entered into a portable microcomputer ${ }^{a}$ on 5 days. The focal animal sampling method ${ }^{18}$ of observation was used in which the activity of a foal was recorded during 15-minute periods. Six activities were distinguished: cantering (including galloping, bucking, rearing, and mounting), trotting, walking, grazing (and walking very slowly), standing (standing resting and standing alert), and lying (lying in lateral position and lying in sternal position). All of the different types of activities performed by foals were seen in these measurement sessions, and activities that foals generally performed for a limited period (cantering and trotting) were sufficiently represented. To evaluate which method was most appropriate to perform this study, observations and GPS recordings were compared. For this evaluation, only GPS recordings with a maximum of $1 \%$ missing data were used.

\section{GPS system}

A GPS receiver with an external antenna was used to record foal activity. A VMS ${ }^{\mathrm{b}}$ was used to store the positional data records. This system can store up to 45,045 data posi-

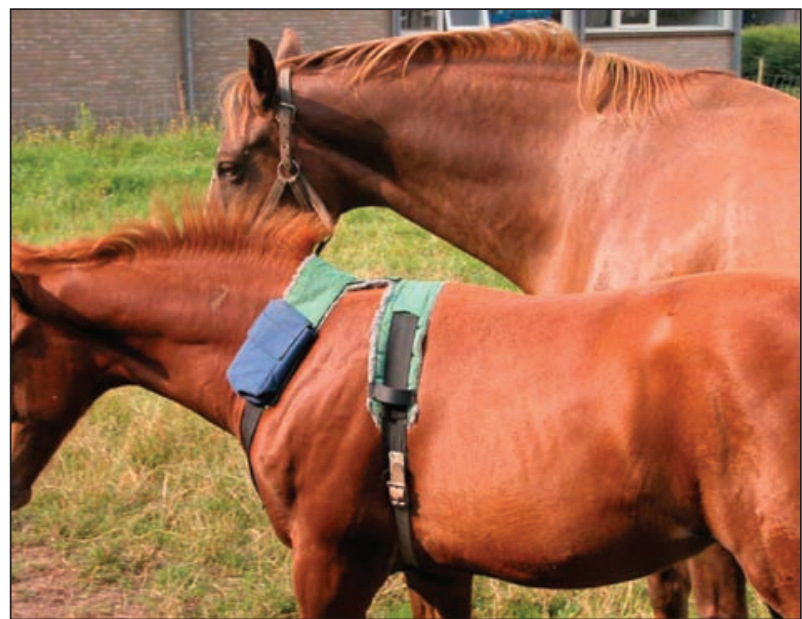

Figure 1-Photograph of a 3-month-old foal with a harness used to carry GPS equipment. tion records, each containing universal coordinated time date, longitude, latitude, altitude, maximum velocity, and GPS receiver measurement quality. Sampling rate was programmed at 1 sample/s.

The experimental foals were fitted with harnesses individually adjusted to their size to carry the GPS equipment (Figure 1). The antennas were placed on the withers, and the GPS receivers and batteries were distributed in right and left canvas bags attached to the harness. Total equipment weight was $1.5 \mathrm{~kg}$ (GPS unit, $400 \mathrm{~g}$; battery pack, $400 \mathrm{~g}$; antenna, $50 \mathrm{~g}$; and harness, $650 \mathrm{~g}$ ). Before the start of the study, each foal was accustomed to carrying the harness with GPS equipment.

\section{GPS data analysis}

Three software programs ${ }^{\mathrm{b}}$ were used with the VMS unit. A VMS utility program was used to configure a VMS unit for use, a VMS capture program was used to download the data from a VMS data logger, and a VMS data extractor was used to convert GPS data into the National Marine Electronics Association format used to export the GPS data to a spreadsheet. ${ }^{c}$ For each second, the velocity of the foal was provided in the output. Velocity was then transformed into activities. For each foal, the individual transition velocities were calculated. Statistical calculations were performed by use of statistical software. ${ }^{\mathrm{d}}$ Pearson correlation coefficients were calculated to evaluate the correlation between observations and GPS recordings.

Observational study of foals, management systems, and environmental conditions-Fifty-nine Dutch Warmblood foals ( 31 colts and 28 fillies) were observed. The foals were 0 to 16 weeks old during the course of the study. They were allocated into 3 categories with respect to group size: single foal with dam $(n=1)$, small groups of foals and mares ( 2 to 5 ), and large groups of foals and mares ( $>10)$. Furthermore, a distinction was made between foals kept at pasture for $24 \mathrm{~h} / \mathrm{d}$ and foals that were stabled during the night. The amount of time that the foals of the latter group spent outside ranged from 6 to 14 hours (mean, 9.3 hours). The foals were studied at different locations in the province of Utrecht and at the Lelystad-based Institute of Horse Husbandry. The Netherlands has a mild, maritime climate. During the observations, temperatures ranged from $14^{\circ}$ to $30^{\circ} \mathrm{C}$ (mean, $20^{\circ} \mathrm{C}$ ), and during $5 \%$ of the observations, it was raining.

\section{Observations}

Field observations were conducted during daylight hours from sunrise to sunset, from May through September 2004. The observations were recorded on a handheld computer $^{\mathrm{a}}$ and analyzed as described. Playing foals were recorded with an analogue video recorder. The following variables were registered for each observation; name of the foal, date and time, observer, age, sex, group size, hours at pasture per day, temperature, rainfall, and wind force. Nine hundred twenty-one focal foal observations were recorded as well as 226 play bouts. Data were transferred from the handheld computer to a laptop computer for long-term storage and analysis.

Table 1-Categories used to classify observations for 6 activities in 59 foals, expressed as percentage of total observed time.

\begin{tabular}{|lccc|}
\hline Activity & Category $\mathbf{1}$ & Category 2 & Category 3 \\
\hline Canter & 0 & $0-1$ & $\geq 1$ \\
Trot & 0 & $0-0.5$ & $\geq 0.5$ \\
Walk & $\leq 5$ & $5-12.5$ & $\geq 12.5$ \\
Grazing & $\leq 10$ & $10-50$ & $\geq 50$ \\
Standing & $\leq 20$ & $20-50$ & $\geq 50$ \\
Lying down & 0 & $0-50$ & $\geq 50$ \\
\hline
\end{tabular}


Table 2-Percentages (mean \pm SD) of observed time foals spent in various activities at different ages.

\begin{tabular}{|lcccc|}
\hline Activity & $\begin{array}{c}\mathbf{0 - 4} \text { weeks } \\
\text { (n= 214) }\end{array}$ & $\begin{array}{c}\mathbf{5 - 8} \text { weeks } \\
\mathbf{( 2 3 9 )}\end{array}$ & $\begin{array}{c}\mathbf{9 - 1 2} \text { weeks } \\
\mathbf{( 2 6 0 )}\end{array}$ & $\begin{array}{c}\text { 13-16 weeks } \\
\text { (208) }\end{array}$ \\
\hline Canter & $1.09 \pm 2.58^{\mathrm{a}}$ & $0.36 \pm 1.04^{\mathrm{b}}$ & $0.30 \pm 0.94^{\mathrm{b}}$ & $0.38 \pm 1.41^{\mathrm{b}}$ \\
Trot & $0.31 \pm 0.76^{\mathrm{a}}$ & $0.19 \pm 0.49^{\mathrm{b}}$ & $0.23 \pm 0.66^{\mathrm{b}}$ & $0.22 \pm 0.92^{\mathrm{b}}$ \\
Walk & $12.34 \pm 10.0^{\mathrm{a}}$ & $10.18 \pm 7.87^{\mathrm{a}}$ & $9.96 \pm 7.42^{\mathrm{a}}$ & $10.72 \pm 7.55^{\mathrm{a}}$ \\
Grazing & $16.74 \pm 17.16^{\mathrm{a}}$ & $28.73 \pm 25.54^{\mathrm{b}}$ & $36.58 \pm 29.59^{\mathrm{c}}$ & $45.72 \pm 30.00^{\mathrm{d}}$ \\
Standing & $38.26 \pm 23.46^{\mathrm{a}}$ & $34.77 \pm 24.86^{\mathrm{a}}$ & $37.14 \pm 27.85^{\mathrm{a}}$ & $28.57 \pm 24.32^{\mathrm{b}}$ \\
Lying down & $31.26 \pm 35.45^{\mathrm{a}}$ & $25.76 \pm 36.49^{\mathrm{b}}$ & $15.80 \pm 30.05^{\mathrm{c}}$ & $14.29 \pm 28.08^{\mathrm{c}}$ \\
\hline
\end{tabular}

${ }^{\mathrm{a}-\mathrm{d}}$ Within a row, values with different superscripts are significantly $(P=0.01)$ different $\mathrm{n}=$ Number of observations.

\section{Observational data analysis}

Data were analyzed by use of special observation software, ${ }^{e}$ and statistical analysis was performed by use of statistical software. ${ }^{\mathrm{d}}$ For the focal foal data, each activity was examined via Pearson $\chi^{2}$ tests to identify differences associated with foal characteristics (age and sex) or management factors (group size and hours kept at pasture). Because $\chi^{2}$ tests were used on cross tabs, each of the activities was categorized into 1 of 3 groups (Table 1). These categories were chosen to obtain approximately equal distribution of observations. Spearman rank order correlation was used to identify associations between age and the different activities. For all analyses, $P<0.05$ was considered significant.

In addition, the daily workload during daytime for foals kept $24 \mathrm{~h} / \mathrm{d}$ at pasture was calculated. Daytime workload $\left(\mathrm{m}^{2} / \mathrm{s}\right)$ was calculated by multiplying velocity by distance. ${ }^{19}$ The distance traveled by the foals was calculated from velocity standards for canter, trot, walk, and graze as 6.0, 3.0, 1.1, and $0.25 \mathrm{~m} / \mathrm{s}$, respectively. These velocity standards were calculated from GPS recordings.

The play data were digitized and observed in slow motion at $1 / 8$ to $1 / 16$ times the normal speed. Five kinds of play were recognized: solitary object play (play with sticks, tussocks, stones, or other objects including play with body parts of the dam), solitary locomotion play (included a wide variety of movements, which are not carried out in combination with another foal and without manipulating objects), social nose play (foals often sniffle each others' noses with oral snapping and front limb kicks, and these actions often initiate other play behavior), social play fight ( 2 or more foals playing together with frequent direct physical contact), and social locomotion play (locomotory play carried out with at least 1 other foal).$^{20}$ Within these kinds of play, 14 actions were discerned and translated into 6 types of movement (Appendix). Each foal participating in a play bout was recorded separately.

\section{Results}

GPS study-Observations and GPS recordings were strongly correlated for walk $(r=0.997 ; P=$ $0.01)$, trot $(r=0.992 ; P=0.01)$, and canter $(r=$ $0.985 ; P=0.01)$. There was moderate correlation between observations and GPS recordings for resting (standing and lying $[r=0.766 ; P=0.05]$ ) and a low correlation for grazing $(r=0.434)$. In the GPS recordings that were used for this evaluation, $0.11 \%$ of total data were missing. However, during other tests, up to $25 \%$ of the scheduled GPS data were not obtained for a variety of reasons.

Observational study-Overall, Dutch Warmblood foals from 0 to 4 months of age spent (mean \pm SD) 0.52 $\pm 1.62 \%$ of the daytime cantering (including galloping,

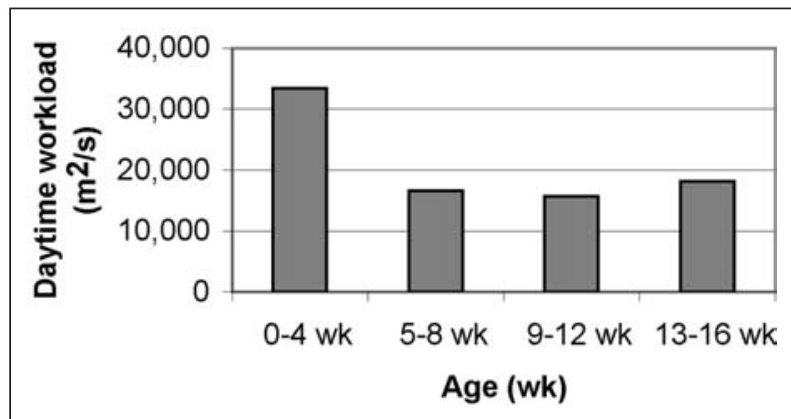

Figure 2-Accumulated daily workload for foals in various age classes.

bucking, rearing, and mounting), $0.24 \pm 0.71 \%$ trotting, $10.74 \pm 8.27 \%$ walking, $32.00 \pm 28.13 \%$ grazing, $34.85 \pm 25.53 \%$ standing, and $21.64 \pm 33.39 \%$ lying There were large individual differences among foals.

\section{Age and sex}

Overall, the amount of observed time the foals spent moving (cantering, trotting, and walking) and lying decreased, and the amount of time spent grazing increased with increasing age (Table 2). For colts (except for colts 13 to 16 weeks old) and fillies combined, time spent cantering $(r=-0.252 ; P=0.01)$ and trotting $(r=-0.137 ; P=0.01)$ decreased with increasing age. Foals in the first month of life spent significantly more time cantering $(P<0.001)$ and trotting $(P=0.003)$ than all older foals. Only in the fourth month was a significant difference detected between colts and fillies; in that month, colts spent significantly $(P=0.03)$ more time cantering than fillies. Colts also spent significantly $(P=0.006)$ more time walking than fillies, particularly in the first month of life. There was a negative correlation between time spent walking and age, although this correlation was not significant $(r=-0.048 ; P=0.143)$. Time spent grazing increased rapidly with increasing age $(r=0.341 ; P=0.01)$. Fillies spent more time grazing than colts $(P<0.001)$. The amount of time spent standing remained relatively constant throughout the first 3 months of life, although foals in the fourth month of life spent less time standing than younger foals $(P=0.001)$. In the fourth month of life, colts spent more time standing than fillies $(P=0.01)$. Time spent lying decreased with increasing age $(r=-0.238 ; P<0.01)$.

\section{Workload}

Daytime workload was calculated for the 4 age groups (Figure 2). Total observed daytime workload in 
the first month of life appeared to be approximately twice as much as that during each of the following 3 months.

\section{Hours at pasture}

Mean \pm SD for observed time spent on all activities of foals kept at pasture for $24 \mathrm{~h} / \mathrm{d}$ and of foals that were stabled during the night was calculated (Table 3). As a percentage of observed time at pasture, foals that were stabled at night spent more time cantering $(P<0.001)$, trotting $(P=0.043)$, and grazing $(P<0.001)$ and less time lying down $(P<0.001)$. For observed times spent walking or standing at pasture, no significant differ-

Table 3-Percentages (mean \pm SD) of observed time foals spent in various activities for foals kept $24 \mathrm{~h} / \mathrm{d}$ at pasture and foals that were stabled at night.

\begin{tabular}{|lcc|}
\hline Activity & $\begin{array}{c}\text { Pasture } \\
(\mathbf{n}=\mathbf{7 9 9})\end{array}$ & $\begin{array}{c}\text { Stable (night) } \\
\text { (122) }\end{array}$ \\
\hline Canter & $0.45 \pm 1.31$ & $0.98 \pm 2.91$ \\
Trot & $0.22 \pm 0.70$ & $0.34 \pm 0.80$ \\
Walk & $10.60 \pm 8.36$ & $11.64 \pm 7.66$ \\
Grazing & $30.26 \pm 27.64$ & $43.34 \pm 28.82$ \\
Standing & $35.06 \pm 26.00$ & $33.49 \pm 22.45$ \\
Lying down & $23.38 \pm 34.33$ & $10.20 \pm 23.49$ \\
\hline
\end{tabular}

See Table 2 for key.

Table 4-Percentages (mean \pm SD) of observed time foals kept $24 \mathrm{~h} / \mathrm{d}$ at pasture spent in various activities for foals kept in different group sizes.

\begin{tabular}{|c|c|c|c|}
\hline Activity & $\begin{array}{c}N=1 \\
(n=351)\end{array}$ & $\begin{array}{c}N=2-5 \\
(365)\end{array}$ & $\begin{array}{c}N>10 \\
(205)\end{array}$ \\
\hline Canter & $0.50 \pm 1.38$ & $0.41 \pm 1.14$ & $0.45 \pm 1.47$ \\
\hline Trot & $0.20 \pm 0.58$ & $0.25 \pm 0.82$ & $0.19 \pm 0.58$ \\
\hline Walk & $9.82 \pm 8.03$ & $11.16 \pm 8.66$ & $10.73 \pm 8.22$ \\
\hline Grazing & $30.04 \pm 28.47$ & $28.25 \pm 26.72$ & $34.33 \pm 27.76^{*}$ \\
\hline Standing & $36.96 \pm 26.79$ & $37.37 \pm 27.02$ & $27.94 \pm 21.17^{*}$ \\
\hline Lying down & $22.48 \pm 33.80$ & $22.50 \pm 33.61$ & $26.35 \pm 36.39$ \\
\hline \multicolumn{4}{|c|}{$\begin{array}{l}\text { *Significantly }(P<0.001) \text { different from both other groups. } \\
N=\text { No. of foal-dam pairs in the group. } \\
\text { See Table } 2 \text { for remainder of key. }\end{array}$} \\
\hline
\end{tabular}

ences were detected between foals that were stabled at night and foals kept at pasture for $24 \mathrm{~h} / \mathrm{d}$.

\section{Group size}

Foals kept in large groups $(\mathrm{n}>10)$ spent more time grazing $(P=0.001)$ and less time standing $(P<$ 0.001 ) than foals kept in smaller groups (Table 4). There were no significant differences among the 3 groups in time spent cantering, trotting, walking, or lying.

\section{Play}

Play occurred more frequently among colts (409 incidents) than among fillies (174 incidents). There were not enough foals in the age category of 13 to 16 weeks to allow reliable evaluation of their play behavior. There was a considerable difference in the type of movement per different type of play among the different age categories but not between sexes (Table 5). During the first month, there was relatively more solitary play (28.6\%) than in the 2 following periods (4.3\% in the second month and $4.8 \%$ in the third month).

\section{Discussion}

Discriminating between walk, trot, and canter was possible by use of the GPS. However, it was necessary to calculate transition velocities for each individual foal, and because there is an overlap in the velocity ranges at which gaits are used, especially for trot and canter ${ }^{21}$ it was never possible to distinguish with $100 \%$ certainty between the different gaits. Also, transition velocities could change with the age of the foal. It was impossible to distinguish between lying and standing with the GPS only. This problem might be rectified by use of a lying-standing sensor, as was used in a previous study ${ }^{11}$ of sheep. It was also difficult to distinguish between resting (lying-standing) and grazing. When a foal is grazing at the same place for an extended time, velocity does not change. Jaw movement sensors could be used to monitor this activity, ${ }^{11}$ as could sensors for

Table 5-Percentages of types of movement resulting from various types of play in foals of various ages.

\begin{tabular}{|c|c|c|c|c|c|c|c|c|}
\hline \multirow[b]{2}{*}{ Age } & \multirow[b]{2}{*}{ Play type } & \multicolumn{6}{|c|}{ Movement type } & \multirow[b]{2}{*}{ Total minutes (\%) } \\
\hline & & Vertical & $\begin{array}{l}\text { Horizontal } \\
\text { slow }\end{array}$ & $\begin{array}{c}\text { Horizontal } \\
\text { fast }\end{array}$ & Combi & Mounting & Kicking & \\
\hline $\begin{array}{l}0-4 \text { wk } \\
n=42\end{array}$ & $\begin{array}{l}\text { Sol obj play } \\
\text { Sol loc play } \\
\text { Nose play } \\
\text { Play fight } \\
\text { Loc play }\end{array}$ & $\begin{array}{l}1.0 \\
2.9 \\
0.5 \\
5.6 \\
1.0\end{array}$ & $\begin{array}{l}69.7 \\
46.9 \\
95.4 \\
89.5 \\
59.9\end{array}$ & $\begin{array}{r}0.0 \\
39.1 \\
0.0 \\
1.7 \\
31.3\end{array}$ & $\begin{array}{r}0.0 \\
11.1 \\
0.0 \\
0.2 \\
6.6\end{array}$ & $\begin{array}{l}0.0 \\
0.0 \\
0.0 \\
0.0 \\
0.0\end{array}$ & $\begin{array}{r}29.3 \\
0.0 \\
4.1 \\
3.0 \\
1.2\end{array}$ & $\begin{array}{l}2: 52(9.9) \\
5: 24(18.7) \\
4: 29(15.5) \\
10: 16(35.5) \\
5: 51(20.3)\end{array}$ \\
\hline $\begin{array}{l}5-8 w k \\
n=280\end{array}$ & $\begin{array}{l}\text { Sol obj play } \\
\text { Sol loc play } \\
\text { Nose play } \\
\text { Play fight } \\
\text { Loc play }\end{array}$ & $\begin{array}{l}2.9 \\
6.7 \\
0.0 \\
5.6 \\
1.6\end{array}$ & $\begin{array}{l}82.4 \\
37.7 \\
98.7 \\
91.7 \\
67.2\end{array}$ & $\begin{array}{r}0.0 \\
37.5 \\
0.3 \\
1.5 \\
28.2\end{array}$ & $\begin{array}{r}0.0 \\
16.2 \\
0.0 \\
0.3 \\
2.5\end{array}$ & $\begin{array}{l}0.0 \\
0.0 \\
0.1 \\
0.1 \\
0.0\end{array}$ & $\begin{array}{r}14.7 \\
1.9 \\
0.9 \\
0.8 \\
0.5\end{array}$ & $\begin{array}{l}2: 02(0.7) \\
12: 13(3.6) \\
69: 18(20.5) \\
162: 50(47.8) \\
92: 38(27.4)\end{array}$ \\
\hline $\begin{array}{l}9-12 \mathrm{wk} \\
\mathrm{n}=254\end{array}$ & $\begin{array}{l}\text { Sol obj play } \\
\text { Sol loc play } \\
\text { Nose play } \\
\text { Play fight } \\
\text { Loc play }\end{array}$ & $\begin{array}{l}4.2 \\
4.3 \\
0.1 \\
6.7 \\
0.8\end{array}$ & $\begin{array}{l}66.1 \\
33.1 \\
99.4 \\
88.3 \\
60.5\end{array}$ & $\begin{array}{r}9.7 \\
51.6 \\
0.3 \\
3.6 \\
35.4\end{array}$ & $\begin{array}{l}0.0 \\
9.3 \\
0.0 \\
0.5 \\
2.5\end{array}$ & $\begin{array}{l}3.0 \\
0.6 \\
0.0 \\
0.1 \\
0.1\end{array}$ & $\begin{array}{r}17.0 \\
1.1 \\
0.2 \\
0.8 \\
0.7\end{array}$ & $\begin{array}{l}3: 07(1.0) \\
11: 41(3.8) \\
58: 22(19.1) \\
133: 18(43.7) \\
98: 44(32.4)\end{array}$ \\
\hline
\end{tabular}


position tracking of the foal's head (up or down). Head position sensors have been used in collars on sheep, horses, and mouflon. ${ }^{22}$ In a study ${ }^{16}$ of activities of cattle, the highest discriminatory power for classifying activity (resting, grazing, and walking) was based on calculated distances, whereas velocity did not have discriminatory power.

Missing data were the major problem with the GPS recordings because trees and large buildings interfere with radio signals from the satellites. The rate of successful GPS location determinations decreases as tree-cover density increases. ${ }^{23}$ The GPS equipment was also easily damaged by normal foal activity. Furthermore, when the antenna was placed on the withers of a foal, reception of radio signals from the satellites by the GPS receiver was not optimal when the foal was lying laterally.

From the preliminary GPS study, it was concluded that advantages of the system in a practical and logistical sense did not outweigh the unreliability and its inability to discriminate between certain activities. Therefore, it was decided to conduct the remainder of the study with handheld computer-assisted observations only.

The amount of observed time spent on locomotion activities of the young (age, 0 to 4 months) Dutch Warmblood foals (11.6\%) was similar to data reported for pastured Przewalski Horse foals kept in zoos (12.2\%), which were also observed during daytime hours. ${ }^{10}$ Both values are close to the value (12.9\%) reported for free-living Camargue foals, ${ }^{9}$ suggesting that locomotion activity in the foals is more or less equally distributed over the entire 24-hour day. Also, the authors have seen such evenly spread times in Icelandic horses, in which weather was of more importance than time of day. Although the number of studies in free-living populations that report on locomotion activity is limited, these results suggest an affirmative answer to the hypothesis that domestically managed foals will exercise at a level comparable with free-living foals.

Overall, with increasing age, Dutch Warmblood foals spent less time moving around and lying and more time grazing, compared with younger ages. This is consistent with Boy and Duncan's ${ }^{9}$ suggestion that the milk diet obviates the need for time-consuming grazing and allows young foals to invest time in sleep and exploration of their physical and social environment. A decrease in time spent cantering and trotting was also observed in Camargue horse foals. ${ }^{9}$ Przewalski foals spent the greatest amount of time performing locomotion activities during the second month of their lives, ${ }^{10}$ but in the present study, Dutch Warmblood foals spent the greatest amount of time moving during their first month. Solitary play was most common during this month, whereas social play was most common later in life. In the fourth month of their lives, colts spent significantly more time cantering than fillies. In fact, colts spent long periods play-fighting together in pairs. Playing occurred more frequently among colts than fillies and may reflect training for their different social roles and activities later in life. These differences in play behavior were also observed in New Forest pony foals. ${ }^{24}$
An interesting observation was that the daytime workload of foals in the first month of life was approximately twice that of older foals. This was mainly caused by the larger amount of cantering foals performed during the first month of life. It has been suggested that the responsiveness of the collagen network of the extracellular matrix of articular cartilage to conditioning by mechanical stimuli is inversely related to the turnover rate of the tissue, which is known to decline rapidly with increasing age before becoming almost nil in mature individuals. ${ }^{25,26}$ It is therefore probable that the first month of life is the most crucial with respect to the influence of exercise on the development of the musculoskeletal system. If this is true, keeping newborn foals at pasture as much as possible, therefore, seems a wise thing to do so that they have ample opportunity to exercise and to stimulate correct development of tissues of the musculoskeletal system.

There are various types of locomotion activity. Foals (and horses in general) spend most of their time performing low-impact locomotion activity, such as walking and grazing, and they spend only a small amount of time in high-impact locomotion activity. Young foals spend little time trotting but more time cantering. This leads to fairly high loading intensity of the musculoskeletal structures. Play leads to still other types of loading. Absolute force values as exerted on the developing tissues are probably not substantially different from those created by cantering, but play activities result in other loading directions, including eccentric loading and loading out of the sagittal plane, which might be important for correct development of musculoskeletal structures.

As expected, foals that were stabled part of the day spent more of the observed time cantering, trotting, and grazing and less time lying down during the hours they were kept at pasture, compared with foals kept at pasture for $24 \mathrm{~h} / \mathrm{d}$. This behavior was probably compensatory for the time they were stabled, in which little spontaneous cantering and trotting were possible. It is likely that the compensation in locomotion activities was not $100 \%$. In this study, no nighttime observations were made. However, if indeed daytime and nighttime activities of horses are not substantially different, as alluded to earlier, extrapolation of the data from the part-time stabled foals would be possible. In that instance, locomotion activity would be less in that group for the canter, trot, and grazing categories than in the foals kept for $24 \mathrm{~h} / \mathrm{d}$ at pasture.

Apart from a decrease in exercise load that might affect the development of musculoskeletal tissues, part-time confinement of young foals can also be questioned from an ethologic viewpoint. Horses are social animals, preferring to associate with others of their own sex and age. During the time a mare and foal are stabled, there is usually an absence of opportunities for social contact with other horses and foals.

Surprisingly, group size did not affect the amount of time spent cantering and trotting. It was expected that foals kept in large groups would play more and, thus, spend more time performing locomotion activities than foals kept only with their dam. Although foals kept in large groups probably are more challenged to 
play, foals kept alone with the dam appear to compensate and use other occasions to perform locomotion activities; for example, as a reaction to environmental factors (eg, traffic, people, and other horses in the neighborhood), they play alone or with the mare. The only difference caused by group size was that foals kept in large groups spent more time grazing than the other foals, whereas the other foals spent more time standing. A possible explanation may be that the foals kept in large groups were more stimulated to graze and taste plants because of the larger size of the plots, which made the forage sources more heterogeneous. Horses prefer some degree of mixture in their grazing. ${ }^{27}$ Although group size did not have an effect on locomotion activity as such, there were substantial influences in other factors. Foals kept in groups are able to play with each other. Play provides an opportunity to acquire and test motor and social skills as well as social relationships. ${ }^{28}$ Therefore, keeping foals in groups of mares and foals seems more appropriate than keeping them solitary with their dam.

Data from this study can be seen as baseline data for Dutch Warmbloods and, possibly, other breeds managed in a similar manner. It would be interesting to conduct comparable studies in horses that are kept under different management conditions, such as in mixed herds, because there seems to be considerably more play among foals, yearlings, young adults, and some mature adults living in a natural social harem and bachelor group organization than in mare and foal pairs or herds. ${ }^{20,29}$ At the other end of the spectrum, data from this study may serve as a reference to critically evaluate management systems in which spontaneous exercise is severely limited.

a. Psion Workabout, Psion PLC, London, England.

b. GPSat Systems Australia Pty Ltd, Victoria, Australia.

c. Excel, Microsoft Corp, Redmond, Wash.

d. SPSS, version 10.0, SPSS Inc, Chicago, Ill

e. The Observer, Noldus Information Technology, Wageningen, The Netherlands.

\section{Appendix}

Definitions of the 6 basic motion patterns resulting from various types of behavior during play in foals.

\begin{tabular}{|ll|}
\hline Direction of movement & Behavior \\
\hline Vertical & Up + down \\
Horizontal slow & Stand + 1 step + walk \\
Horizontal fast & Trot + canter + gallop \\
Combination (vertical + horizontal) & Frolic + jump + buck \\
Mounting & Mounting \\
Kicking & Thoracic limb kick + pelvic \\
& limb kick \\
\hline
\end{tabular}

\section{References}

1. Fagen RM, George TM. Play behavior and exercise in young ponies. Behav Ecol Sociobiol 1977;2:267-269.

2. Helminen HJ, Hyttinen MM, Lammi MJ, et al. Regular joint loading in the youth assists in the establishment and strengthening of articular cartilage and contributes to the prevention of osteoarthrosis later in life: a hypothesis. J Bone Miner Metab 2000;18:245-257.

3. Van Weeren PR, Barneveld A. Study design to evaluate the influence of exercise on the development of the musculoskeletal system of foals up to age 11 months. Equine Vet J Suppl 1999;31:4-8.
4. Barneveld A, Van Weeren PR. Conclusions regarding the influence of exercise on the development of the equine musculoskeletal system with special reference to osteochondrosis. Equine Vet J Suppl 1999;31:112-119.

5. Van Weeren PR, Brama PAJ, Barneveld A. Exercise at young age may influence the final quality of the equine musculoskeletal system, in Proceedings. 46th Annu Meet Am Assoc Equine Pract 2000;29-35.

6. McIlwraith CW. Report: Global Equine Research Alliance to reduce musculoskeletal injury in the equine athlete. Equine Vet Educ 2000;12:260-262

7. Dykgraaf S, Firth EC, Rogers CW, et al. Effect of exercise on cartilage and subchondral bone of young thoroughbred horses, in Proceedings. Am Assoc Equine Pract Focus Joint Meet 2004;220-225.

8. Van Weeren PR, Brama PAJ, DeGroot J, et al. Conditioning of articular cartilage through early exercise: the effect on post-translational modifications of collagen, in Proceedings. Am Assoc Equine Pract Focus Joint Meet 2004;234-242.

9. Boy V, Duncan P. Time-budgets of Camargue horses. I. Developmental changes in the time-budgets of foals. Behaviour 1979;71:187-202.

10. Boyd LE. Ontogeny of behavior in Przewalski horses. Appl Anim Behav Sci 1988;21:41-69.

11. Rutter SM, Beresford NA, Roberts G. Use of GPS to identify the grazing areas of hill sheep. Comp Electron Agric 1997;17:177-188.

12. Steiner I, Bürgi C, Werffeli S, et al. A GPS logger and software for analysis of homing in pigeons and small mammals. Physiol Behav 2000;71:589-596.

13. Turner LW, Udal MC, Larson BT, et al. Monitoring cattle behaviour and pasture use with GPS and GIS. Can J Anim Sci 2000;80:405-413.

14. Ganskopp D. Manipulating cattle distribution with salt and water in large arid-land pastures: a GPS/GIS assessment. Appl Anim Behav Sci 2001;73:251-262.

15. Biro D, Guilford T, Dell'Omo G, et al. How the viewing of familiar landscapes prior to release allows pigeons to home faster: evidence from GPS tracking. J Exp Biol 2002;205:3833-3844.

16. Schlecht E, Hülsebusch C, Mahler F, et al. The use of differentially corrected global positioning system to monitor activities of cattle at pasture. Appl Anim Behav Sci 2004;85:185-202.

17. Ungar ED, Henkin Z, Gutman M, et al. Inference of animal activity from GPS collar data on free-ranging cattle. J Range Manage 2005;58:256-266

18. Altmann J. Observational study of behavior; sampling methods. Behaviour 1974;49:227-267.

19. Rogers CW, Firth EC. Musculoskeletal responses of 2-yearold Thoroughbred horses to early training. 2. Measurement error and effect of training stage on the relationship between objective and subjective criteria of training workload. N Z Vet J 2004;52:272-279.

20. McDonnell SM, Poulin A. Equid play ethogram. Appl Anim Behav Sci 2002;78:263-290.

21. Leach D, Cymbaluk NF. Relationships between stride length, stride frequency, velocity, and morphometrics of foals. Am J Vet Res 1986;47:2090-2097.

22. Scheibe KM, Schleusner TH, Berger A, et al. ETHOSYS-new system for recording and analysis of behaviour of free-ranging domestic animals and wildlife. Appl Anim Behav Sci 1998;55:195-211.

23. Rempel RS, Rodgers AR. Effects of differential correction on accuracy of a GPS animal location system. J Wildl Manage 1997;61:525-530.

24. Tyler SJ. The behaviour and social organisation of the New Forest ponies. Anim Behav Monogr 1972;5:85-196.

25. Maroudas A. Metabolism of cartilaginous tissue: a quantitative approach. In: Maroudas A, Holborrow EJ, eds. Studies in joint diseases. London: Pitman Medical, Tunbridge Wells, 1980;59-66.

26. Van Weeren PR, Brama PAJ. Equine joint disease in the light of new developments in articular cartilage research. Pferdeheilk 2003;19:336-344.

27. Goodwin D, Davidson HPB, Harris P. Sensory varieties in concentrate diets for stabled horses: effects on behaviour and selection. Appl Anim Behav Sci 2005;90:337-349.

28. Waring GH. Play. In: Horse behaviour. 2nd ed. Norwich, NY: Noyes Publications, William Andrew Publishing, 2003;83-90.

29. Sigurjónsdóttir H, van Dierendonck MC, Thorhallsdottir AG. Social relationships in herds of Icelandic horses-does the absence of stallions make a difference? Behaviour 2003;140:783-804. 